\title{
Intersetorialidade e transversalidade: a estratégia dos programas complementares do Bolsa Família
}

Trajano Augustus Quinhões e Virginia Maria Dalfior Fava

\section{Introdução}

Embora a distribuição de renda no Brasil tenha melhorado nos últimos anos, demonstrada pela queda de 8,5\% no coeficiente de Gini ${ }^{1}$ entre 1995 e 2005, passando de 0,585 para 0,544, segundo o Instituto de Pesquisa Econômica e Aplicada (Ipea), em 2007, 9,1\% das famílias brasileiras viviam em situação de indigência e 25,6\% em situação de pobreza. Contudo, a situação de vulnerabilidade dessas famílias não se restringe à insuficiência de renda para suprirem suas necessidades básicas, pois também faltam meios para a inserção no mercado de trabalho ou para o desenvolvimento de alternativas de geração de renda compatíveis com uma existência digna.

A superação da pobreza, da desigualdade e da exclusão social no Brasil é umdesafio que extrapola a capacidade de um único nível de governo e requerem a adoção de políticas que incorporem a intersetorialidade e a transversalidade, e consigam atender as demandas dos segmentos excluídos. 
Desde que foi criado em 2003, o Programa Bolsa Família (PBF) tem contribuído para o enfrentamento da pobreza, da exclusão social e da desigualdade, promovendo ações que impactam em diferentes segmentos da sociedade. A transferência direta de renda a 11,1 milhões de famílias pobres e extremamente pobres promove um impacto sobre a desigualdade. O monitoramento do cumprimento das condicionalidades de educação e saúde, que mobiliza os ministérios do Desenvolvimento Social e Combate à Fome (MDS), da Educação e da Saúde, governos estaduais e municipais, reforça o compromisso do setor público de garantir melhores condições de acesso a esses serviços, assim como o dever das famílias de matricular as crianças nas escolas e realizar as visitas médicas necessárias. A articulação de programas e ações complementares contribui para o desenvolvimento de capacidades das famílias pobres e extremamente pobres, para a sua inclusão socioeconômica e sua emancipação do programa, sob uma perspectiva de longo prazo.

Este artigo descreve a estratégia implementada em 2006 e 2007 pelo Programa Bolsa Família para a articulação de programas e ações complementares às transferências de renda, enfatizando sua contribuição para o enfrentamento da desigualdade e da exclusão social no Brasil. Também apresenta os resultados preliminares alcançados por alguns desses programas executados em nível federal.

O artigo está organizado em cinco partes: 1) discussão teórica sobre desigualdade, exclusão social e questão social; 2) principais programas de transferência de renda no Brasil; 3) Programa Bolsa Família; 4) estratégia de articulação dos programas complementares à transferência de renda, implementada em 2006 e 2007; e 5) conclusões.

\section{Desigualdade, exclusão social e a questão social}

A desigualdade é uma das características mais marcantes da sociedade brasileira e se manifesta em diversas dimensões: geográfica, econômica, de trabalho, educacional, de acesso à saúde, de gênero, de raça, entre outras. Segundo a Síntese de Indicadores Sociais do IBGE (IBGE, 2002), 1\% dos brasileiros mais ricos acumula o mesmo montante de rendimentos dos 50\% mais pobres, e os $10 \%$ mais ricos ganham 18 vezes a renda dos $40 \%$ mais pobres. A metade dos trabalhadores brasileiros ganha até dois salários mínimos e mais da metade da população ocupada não contribui para a Previdência. A desigualdade de rendimentos no Brasil acarreta outros prejuízos sociais, como por exemplo: $80 \%$ dos domicílios dos $10 \%$ mais ricos têm saneamento adequado contra um terço dos $40 \%$ mais pobres (IBGE, 2002).

A atual configuração de desigualdades é mais ampla do que em outras épocas, com múltiplos eixos, novos problemas e desafios; um mosaico cada vez mais diverso de situações de pobreza, riqueza, fracasso e êxito (BRUGuÉ, 2002) decorrente de um processo de exclusão social que é característico da sociedade pós-industrial.

O debate teórico sobre a desigualdade possui duas vertentes principais. A primeira refere-se a qual desigualdade está sendo discutida. De acordo com Sen (1992), todas as abordagens da ética dos arranjos sociais defendem algum tipo de igualdade em específico, relacionando-a a alguma necessidade relevante e, em algum nível, a todas as pessoas envolvidas. Segundo o 
autor, não haveria uma única igualdade ou desigualdade, mas várias. A segunda vertente consiste na origem ou na responsabilidade sobre a desigualdade. Kerstenetzky (2000) aponta que as desigualdades entre as pessoas podem ser explicadas segundo duas perspectivas: 1) Rawlsiana, de que os indivíduos são responsáveis por suas escolhas, em um mundo onde estão plenamente disponíveis o conhecimento e a habilidade para entender e optar inteligentemente a partir das alternativas existentes; e 2) de Amartya Sen, de que a incerteza factual e as formas de condicionamento social fazem as pessoas perderem a coragem de escolher e de desejar. Nesse contexto, a relatividade social e cultural das necessidades parece explicar porque alguns indivíduos se comportam no sentido de atingir seus objetivos, enquanto outros não o fazem. Na segunda perspectiva, o combate à desigualdade requer a redução ou eliminação de sentimentos de vergonha e de baixa estima.

A desigualdade promove e ao mesmo tempo decorre da exclusão social que, apesar de atualmente ser reconhecida como intensa, não é institucionalizada na maioria das situações e se processa por mecanismos cada vez mais sutis. A institucionalização da exclusão social é a sua forma mais extrema. Qualquer sociedade que a faça é injusta porque isso representa uma negação da equidade participativa. Estar excluído é pior do que estar incluído marginalmente ou de maneira subordinada.

Brugué (2002) define exclusão social como a impossibilidade ou a dificuldade de acessar os mecanismos de desenvolvimento pessoal e inserção sócio-comunitária, e os sistemas preestabelecidos de proteção. A exclusão não implica somente reprodução ampliada das desigualdades, mas fraturas no tecido social e ruptura de certas coordenadas básicas de integração.
$\mathrm{O}$ autor entende a exclusão como um fenômeno estrutural, um processo dinâmico, ao invés de uma situação estável; um fenômeno multifatorial e multidimensional, como uma estrutura poliédrica; e um fenômeno politizável. ${ }^{2}$

A exclusão social também pode ser definida a partir do conceito de cidadania. Segundo Fleury (2004a, p.3), a exclusão é a "não incorporação de uma parte significativa da população à comunidade social

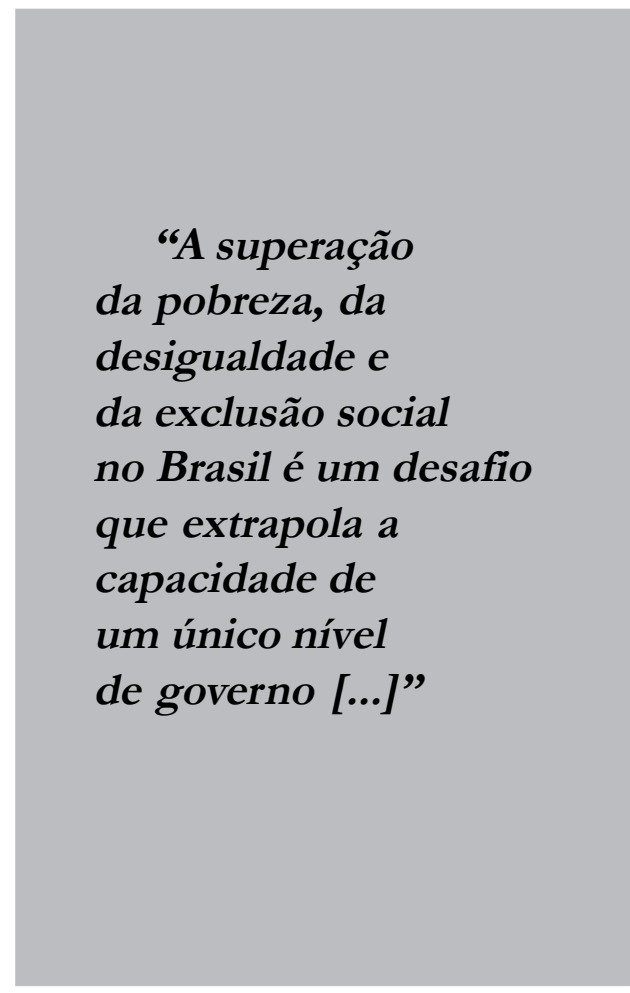

e política, negando seus direitos de cidadania - destituindo-a de direitos ou envolvendo a desigualdade de tratamento ante a lei e as instituições públicas - e impedindo seu acesso à riqueza produzida".

Os âmbitos e as circunstâncias que favorecem a exclusão social delimitam diferentes conceitos para a cidadania e descrevem as condições sob as quais se dá a exclusão. Diante dessa diversidade de fatores e 
conceitos, Fraser (2003) propõe um novo enfoque, o da exclusão social como uma injustiça bidimensional, que exige uma resposta que associe política de redistribuição com política de reconhecimento. Segundo a autora (2003), o conceito de exclusão social pode situar-se no mesmo campo dos conceitos de pobreza e iniquidade, definida a partir do impedimento do acesso à riqueza material e imaterial; ou pode significar a negação de reconhecimento e a falta de respeito à identidade ou aos direitos de determinado grupo. Assim, a autora defende que a fórmula geral para remediar a injustiça social é a eliminação dos impedimentos para a equidade participativa, sejam obstáculos institucionalizados ou impedimentos econômicos e culturais.

A exclusão social pode ser extrema e radical, mas usualmente costuma ser focalizada em esferas específicas. Diante da capacidade de um indivíduo poder ser excluído de uma ou mais esferas da sociedade - da participação política, da vida laboral, da vida familiar, das esferas públicas, da educação e de outras -, Fraser (2003) empregou o conceito de exclusão diferenciada e de cidadania diferenciada, desenvolvido originalmente por Young $(1989)^{3}$. Para uma visualização do conceito de cidadania diferenciada, Brugué (2002) propõe uma matriz de condições altamente vulneráveis a processos de exclusão social (Quadro 1), em que compara dois tipos de variáveis: âmbitos onde podem ocorrer fatores de exclusão e circunstâncias intensificadoras desses fatores. Os âmbitos onde se dariam os fatores de exclusão seriam: econômico, laboral, educacional, sócio-sanitário, urbanoterritorial, familiar-relacional e de política ou de cidadania. As circunstâncias seriam o sexo, a idade, a etnia e a classe social.

A política social, até o princípio dos anos 1980, era organizada como uma política de classe. A oferta de serviços e produtos era centralizada e padronizada e se dava em torno dos sistemas nacionais de saúde e de seguro-social. As políticas públicas que incorporaram a filosofia do Estado de Bem-estar Social têm sido incapazes de enfrentar e solucionar os atuais desafios, caracterizados por demandas heterogêneas, por formas particulares de emprego e pelo aumento do desemprego (BRugué, 2002).

A atual situação de desigualdade, pobreza e violência faz emergir a exclusão como uma questão social (FLEURY, 2004a). A exclusão social, condição que sempre existiu na sociedade latino-americana, aparece como uma problemática que exige resposta por parte do governo e da sociedade e, portanto, como questão social, porque ameaça a organização social,

\section{Quadro 1: Âmbitos onde podem operar fatores de exclusão}

\begin{tabular}{|c|c|c|c|c|c|c|c|}
\hline \multicolumn{8}{|c|}{ Âmbitos onde podem operar fatores de exclusão } \\
\hline $\mathrm{CIE}^{*}$ & $\begin{array}{l}\text { Exclusão } \\
\text { econômica }\end{array}$ & $\begin{array}{l}\text { Exclusão } \\
\text { laboral }\end{array}$ & $\begin{array}{l}\text { Exclusão } \\
\text { educativa }\end{array}$ & $\begin{array}{l}\text { Exclusão } \\
\text { sócio - } \\
\text { sanitária }\end{array}$ & $\begin{array}{l}\text { Exclusão } \\
\text { urbana - } \\
\text { territorial }\end{array}$ & $\begin{array}{l}\text { Exclusão } \\
\text { familiar - } \\
\text { relacional }\end{array}$ & $\begin{array}{l}\text { Exclusão de } \\
\text { política/de } \\
\text { cidadania }\end{array}$ \\
\hline Sexo & \multirow{4}{*}{\multicolumn{7}{|c|}{ Coletivos de população altamente vulneráveis a processos de exclusão social }} \\
\hline Idade & & & & & & & \\
\hline Etnia (origem) & & & & & & & \\
\hline Classe social & & & & & & & \\
\hline
\end{tabular}

* Circunstâncias Intensificadoras da Exclusão Social

Fonte: Brugué (2002, p. 20), Tabela 5, Âmbitos, circunstâncias e condições vulneráveis para a exclusão social. 
a autoridade política e o modelo econômico. Requer políticas e instituições específicas, o posicionamento de diferentes atores da sociedade, novas formas de sociabilidade, a definição de um campo estratégico de luta, a construção de novos sujeitos e novas subjetividades. Demanda novos saberes e tecnologias organizacionais, novas estratégias de reconstrução da ordem política e de enquadramento das demandas sociais e aponta para processos de transformação das estruturas institucionais estatais (Fleury, 2004a). Não obstante, a pobreza novamente reconduz as políticas sociais a uma função de apaziguamento e não por exigências democráticas e de justiça.

As políticas sociais implementadas na última década não têm se esgotado na interação Estado-mercado, pois o mercado não é o único espaço gerador de desigualdades e não é a única esfera social além dos poderes públicos. Assim, o impacto das políticas não tem sido reduzido à mera correção de desigualdades materiais, o que as torna fenômenos complexos e multidirecionais (BRUgué, 2002). As ações públicas implementadas contra a exclusão emergem como iniciativas dos ditos estados de bem-estar, em pleno processo de reestruturação de seus modelos assistenciais.

O Estado é crucial em sociedades em que a cidadania, como dimensão igualitária e cívica, não foi generalizada e que convivem com alto grau de exclusão. Mas a busca da coesão social requer bem mais do que um aumento do papel do Estado. A proposta de "cidadanias diferenciadas", com ênfase nas necessidades dos grupos excluídos, pode promover tensões sobre a capacidade de coesão social e de construção de uma comunidade política a partir de demandas particulares. A redução de desigualdades específicas depende da arti- culação de políticas sensíveis ao atendimento de demandas particulares, direcionadas a realidades locais, e de uma mudança nas políticas sociais, de políticas de integração para políticas de inserção ${ }^{4}$ dos grupos excluídos da sociedade, para que não se construa cidadania sobre inutilidade social (CAStel, 1999).

Os programas de combate à desigualdade e de inclusão social, que têm sido implementados na América Latina na última década, têm indicado novas formas de superação de problemas sociais a partir da articulação entre o Estado e a sociedade. O Programa Bolsa Família (PBF) apresenta algumas dessas características tidas como inovadoras e essenciais às políticas sociais na atualidade, quais sejam: praticar a intersetorialidade e a transversalidade; possibilitar o reconhecimento de demandas de grupos sociais marginalizados e dar condições ao planejamento e à oferta de políticas e de serviços direcionados a essas populações; e permitir que a sociedade civil organizada, nos três níveis de governo, por meio de seus representantes, influencie a agenda de políticas direcionadas aos segmentos excluídos e empobrecidos da sociedade brasileira e monitore as ações implementadas.

\section{Programas focalizados de transferência de renda no Brasil}

A Constituição de 1988 estabeleceu o compromisso de erradicar a pobreza e a marginalização e reduzir as desigualdades sociais e regionais, sendo competência comum da União, estados, Distrito Federal e municípios, o combate às suas causas e aos fatores de marginalização, e a promoção da integração social dos desfavorecidos (CF/88, Art. 23, Inc X). Antes disso, a pobreza era tratada de 
forma isolada e setorial, muitas vezes sob um caráter filantrópico.

O caminho percorrido até a execução desses compromissos federais, por meio da criação dos programas de transferência de renda, teve início em 1995, com o lançamento de programas de renda mínima vinculados à educação em duas cidades do estado de São Paulo (Campinas e Ribeirão Preto) e no Distrito Federal. Em 1996, o Programa Bolsa Escola, desenvolvido em Brasília, foi premiado pelas Nações Unidas e replicado para outras regiões. Em 1998, sete estados (Amapá, Goiás, Tocantins, Alagoas, Minas Gerais, Mato Grosso do Sul e Acre), 45 municípios de São Paulo e nove municípios de outros estados já tinham implantado programas inspirados na experiência brasiliense. Como consequência da expansão dos programas Bolsa Escola, em 2001 o governo decidiu criar o Programa Bolsa Escola Federal, que em 2002 alcançava 5.545 municípios, cinco milhões de crianças e um orçamento de $\mathrm{R} \$ 2$ bilhões. Outra estratégia de transferência de renda, criada em 1997, foi o Programa de Erradicação do Trabalho Infantil (Peti ${ }^{5}$ ), para atender a crianças e adolescentes que exercessem atividades laborais no campo, sendo ampliado, em 1999, zona urbana. Além desses programas, em 2001, o governo federal implementou outras experiências de transferência de renda, como o BolsaAlimentação, o Auxílio-Gás e o Agente Jovem $^{6}$, cuja gestão estava sob a responsabilidade da extinta Secretaria de Assistência Social (Seas).

Atualmente, os principais programas sociais brasileiros que contribuem para a redução da desigualdade de renda são o Benefício de Prestação Continuada (BPC/ Loas) e o Programa Bolsa Família (PBF), que cobrem, juntos, 14,4 milhões de famílias - 2,9 milhões do BPC e 11,5 milhões do PBF, em junho de 2009. Em 2009, foi previsto um gasto aproximado de R\$18,5 bilhões com o BPC e de $\mathrm{R} \$ 11,9$ bilhões com o PBF.

O BPC é um programa que mensalmente transfere renda a pessoas portadoras de deficiências consideradas severas, em qualquer idade, e a idosos maiores de 65 anos. É necessário que o beneficiário apresente renda familiar per capita inferior a $1 / 4$ de salário mínimo. $O$ direito a um salário mínimo mensal para essas pessoas, estabelecido na Carta de 1988 e regulamentado pela Lei Orgânica da Assistência Social (Loas) em 1993, teve sua implementação iniciada em 1995. O Ministério do Desenvolvimento Social e Combate à Fome (MDS) coordena o programa, mas a solicitação do benefício ocorre diretamente nas agências do Instituto Nacional do Seguro Social (INSS), e a seleção de beneficiários é realizada por médicosperitos da Previdência.

Criado no final de 2003, a partir da unificação dos programas preexistentes inspirados no Bolsa Escola, o PBF é um programa de transferência mensal de renda com condicionalidades. O PBF atende a famílias cuja renda per capita seja inferior a $\mathrm{R} \$ 69,00$ mensais e a famílias de gestantes, nutrizes, crianças e adolescentes de até 17 anos, cuja renda per capita seja inferior à $\mathrm{R} \$ 137,00$. Foi criado por medida provisória, posteriormente convertida em lei (BRASIL, 2004a). A seleção dos beneficiários é, em geral, realizada pelos órgãos municipais de assistência social, ficando a gerência do programa sob responsabilidade do MDS e as operações de pagamento a cargo da Caixa Econômica Federal. O recebimento das transferências é condicionado a contrapartidas nas áreas de educação e saúde, de acordo com a composição das famílias beneficiárias (Quadro 2). 
Quadro 2: Condicionalidades do Programa Bolsa Família

\begin{tabular}{|c|c|}
\hline Educação & Saúde \\
\hline $\begin{array}{l}\text { Para famílias com crianças até } 15 \text { anos: } \\
\text { - Efetivar a matrícula das crianças e adoles- } \\
\text { centes de } 6 \text { a } 15 \text { anos em estabelecimentos } \\
\text { de ensino. } \\
\text { - Garantir a frequência escolar de, no } \\
\text { mínimo, } 85 \% \text { da carga horária, informando } \\
\text { a escola quando da impossibilidade de } \\
\text { comparecimento eventual do aluno e apre- } \\
\text { sentando, se for o caso, a devida justificativa. } \\
\text { • Informar os gestores locais de imediato } \\
\text { sobre eventuais mudanças de escola, para } \\
\text { não prejudicar o processo de acompanha- } \\
\text { mento da frequência escolar. }\end{array}$ & $\begin{array}{l}\text { Para gestantes e nutrizes: } \\
\text { - Inscrever-se no pré-natal e comparecer às } \\
\text { consultas na unidade de saúde mais próxima } \\
\text { de sua residência, portando o cartão da } \\
\text { gestante, de acordo com o calendário mínimo } \\
\text { preconizado pelo Ministério da Saúde. } \\
\text {-Participar de atividades educativas ofertadas } \\
\text { pelas equipes de saúde sobre aleitamento ma- } \\
\text { terno e promoção da alimentação saudável. } \\
\text { Para famílias com crianças até } 7 \text { anos: } \\
\text { - Levar as crianças à unidade de saúde ou ao } \\
\text { local de campanhas de vacinação, mantendo } \\
\text { atualizado o calendário de imunização, } \\
\text { conforme preconizado pelo Ministério } \\
\text { da Saúde. } \\
\text { - Levar as crianças à unidade de saúde, } \\
\text { portando o cartão de saúde da criança, para } \\
\text { acompanhamento do estado nutricional e de } \\
\text { desenvolvimento (medição de peso e altura), } \\
\text { conforme o calendário mínimo preconizado } \\
\text { pelo Ministério da Saúde. }\end{array}$ \\
\hline
\end{tabular}

Fonte: Portaria MEC/MDS n 3.789, e MS/MDS n² 2.509, de 2004.

Em termos de direitos e de garantias sociais, há diferenças substanciais entre o BPC e o Bolsa Família. O BPC é um direito social previsto na Constituição e regulamentado por lei ordinária. Todos os indivíduos que preenchem seus critérios de seleção têm direito a recebê-lo, podendo exigi-lo judicialmente. O PBF condiciona a ampliação do número de beneficiários à disponibilidade orçamentária, à estimativa de população pobre e extremamente pobre para cada município e a convênios firmados com os entes federados. Por esses motivos, seria um quasi-direito social. O Ministério do Desenvolvimento Social detectou, no final de 2008, 2,2 milhões de famílias que não recebiam o benefício do Bolsa Família, apesar de reunirem todas as condições de perfil e de renda (Folha de São Paulo, 2009). Para atender a essas famílias, foi definida uma nova estimativa de cobertura do programa. Os cálculos das novas estimativas foram realizados considerando a metodologia denominada Mapas de Pobreza, do Instituto Brasileiro de Geografia e Estatística (IBGE), que reflete de maneira mais fiel alterações socioeconômicas ocorridas nos municípios e o cenário de pobreza em cada cidade.

Outra importante distinção entre o BPC e o PBF é que esse último exige o cumprimento das condicionalidades nas áreas de saúde e de educação. Como pode ser visto no Quadro 3, até setembro de 2007, 
905.445 famílias haviam sido advertidas, 245.857 tiveram seus benefícios bloqueados e 4.153, cancelados, ou seja, foram excluídas do programa por descumprirem condicionalidades. As sanções aplicadas para esses casos são gradativas e tornam-se mais rigorosas à medida que reincidências nos descumprimentos são apuradas, de modo que cada família pode receber até cinco comunicações de alerta para a possibilidade de cancelamento do benefício. Esse desenho é criticado pela flexibilidade com que trata as famílias reincidentes. Contudo, a ideia é reforçar o apoio às famílias mais vulneráveis, por meio de ações de incentivo, em vez de instituir práticas punitivas, como a retirada imediata do incentivo financeiro.

A última distinção a ser destacada entre os dois programas é que o PBF articula, para as famílias beneficiadas, outras ações governamentais que possam complementar a transferência de renda, cuja estratégia será detalhada mais adiante.

\section{O Programa Bolsa Família}

Lançado em outubro de 2003 pela Secretaria Nacional de Renda para a Cidadania (Senarc), do Ministério do Desenvol- vimento Social e Combate à Fome (MDS), o Programa Bolsa Família (PBF) compõe uma das principais estratégias do governo federal para o fortalecimento da agenda de combate à pobreza, por meio da transferência condicionada de renda e da articulação de políticas sociais para a emancipação sustentada das famílias beneficiárias. O programa está presente nos 5.564 municípios brasileiros e no Distrito Federal.

O Bolsa Família unificou quatro programas federais de transferência de renda que focalizavam o mesmo grupo de famílias pobres: Bolsa Escola, Cartão Alimentação, Bolsa-Alimentação e Auxílio-Gás. A partir de 2005, iniciou processo de integração com o Programa de Erradicação do Trabalho Infantil (Peti). A unificação teve como objetivo eliminar ineficiências e duplicidades nas funções administrativas; acabar com sobreposições de público alvo; promover o atendimento de todos os membros da família; melhorar a qualidade do gasto público nas políticas sociais; e fortalecer a agenda de combate à pobreza. As reformas que culminaram na unificação de programas setorializados e na criação do Bolsa Família buscaram, ainda, promover a integração

\section{Quadro 3: Critérios de elegibilidade e valor do benefício do Programa Bolsa Família}

\begin{tabular}{|c|c|c|c|c|c|}
\hline $\begin{array}{l}\text { Situação } \\
\text { da família }\end{array}$ & $\begin{array}{c}\text { Renda } \\
\text { Mensal } \\
\text { per capita }\end{array}$ & $\begin{array}{c}\text { Ocorrência de crianças/ } \\
\text { adolescentes e } \\
\text { nutrizes }\end{array}$ & $\begin{array}{c}\text { Valor do } \\
\text { benefício sem } \\
\text { jovem na } \\
\text { família } \\
\end{array}$ & $\begin{array}{c}\text { Valor do } \\
\text { benefício com } \\
1 \text { jovem }\end{array}$ & $\begin{array}{c}\text { Valor do } \\
\text { benefício com } \\
2 \text { jovens ou }+\end{array}$ \\
\hline \multirow[t]{4}{*}{ Pobreza } & \multirow{4}{*}{$\begin{array}{l}\mathrm{R} \$ 60,01 \mathrm{a} \\
\mathrm{R} \$ 120,00\end{array}$} & Sem ocorrência & $\mathrm{R} \$ 00,00$ & $\mathrm{R} \$ 33,00$ & $\mathrm{R} \$ 66,00$ \\
\hline & & 1 membro & $\mathrm{R} \$ 22,00$ & $\mathrm{R} \$ 55,00$ & $\mathrm{R} \$ 88,00$ \\
\hline & & 2 membros & $\mathrm{R} \$ 44,00$ & $\mathrm{R} \$ 77,00$ & $\mathrm{R} \$ 110,00$ \\
\hline & & $3 \mathrm{ou}+$ membros & $\mathrm{R} \$ 66,00$ & $\mathrm{R} \$ 99,00$ & $\mathrm{R} \$ 132,00$ \\
\hline \multirow{4}{*}{$\begin{array}{l}\text { Extrema } \\
\text { Pobreza }\end{array}$} & \multirow[t]{4}{*}{ Até $\mathrm{R} \$ 60,00$} & Sem ocortência & $\mathrm{R} \$ 68,00$ & $\mathrm{R} \$ 101,00$ & $\mathrm{R} \$ 134,00$ \\
\hline & & 1 membro & $\mathrm{R} \$ 90,00$ & $\mathrm{R} \$ 123,00$ & $\mathrm{R} \$ 156,00$ \\
\hline & & 2 membros & $\mathrm{R} \$ 112,00$ & $\mathrm{R} \$ 145,00$ & $\mathrm{R} \$ 178,00$ \\
\hline & & $3 \mathrm{ou}+$ membros & $\mathrm{R} \$ 134,00$ & $\mathrm{R} \$ 167,00$ & $\mathrm{R} \$ 200,00$ \\
\hline
\end{tabular}


horizontal dos programas anteriores e adicionar um complemento mais forte aos programas locais, já que muitos estados e municípios também possuíam seus próprios programas.

Da Lei no 10.836, de 9 de janeiro de 2004 (Brasil, 2004a), e do Decreto $\mathrm{n}^{\circ}$ 5.209, de 17 de setembro de 2004 (BRAsIL, 2004b), que, respectivamente, cria e regulamenta o Bolsa Família, é possível inferir que, o programa foi idealizado para cumprir objetivos importantes de redução de desigualdades, tais como: contribuir para a promoção do acesso à rede de serviços públicos e, em especial, de saúde, educação e assistência social; combater a pobreza, a fome e promover a segurança alimentar e nutricional; estimular a emancipação sustentada das famílias que vivem em situação de pobreza e extrema pobreza; e promover a intersetorialidade, a complementaridade e a sinergia das ações sociais do poder público.

$\mathrm{O} \mathrm{PBF}$ foi organizado tendo como base seis premissas, que estão formalizadas em sua lei de criação: 1) associação de políticas de combate à pobreza a políticas de promoção da cidadania; 2) estabelecimento de uma nova relação entre o governo federal e os demais entes da Federação, em que a concepção de parceria e de responsabilidade partilhada se contrapõe a um modelo de relação verticalizada; 3) foco na família como unidade da ação do Estado, superando a abordagem fragmentada e segmentada em recortes como idade e sexo, por exemplo; 4) criação de critérios que orientem a universalização da cobertura do programa ao conjunto da população estimada, vivendo em situação de pobreza; 5) participação da sociedade no acompanham ento, fiscalização e controle do program, por meio da criação d instâncias de controle social paritárias e intersetoriais, e a disponibilização de dados e instrumentos que permitam o acompanhamento de sua implementação; e 6) aperfeiçoamento constante dos instrumentos de gestão e de controle dos critérios de elegibilidade.

Para serem beneficiárias do PBF, as famílias são identificadas e inscritas no Cadastro Único para Programas Sociais do Governo Federal (Cadastro Único),

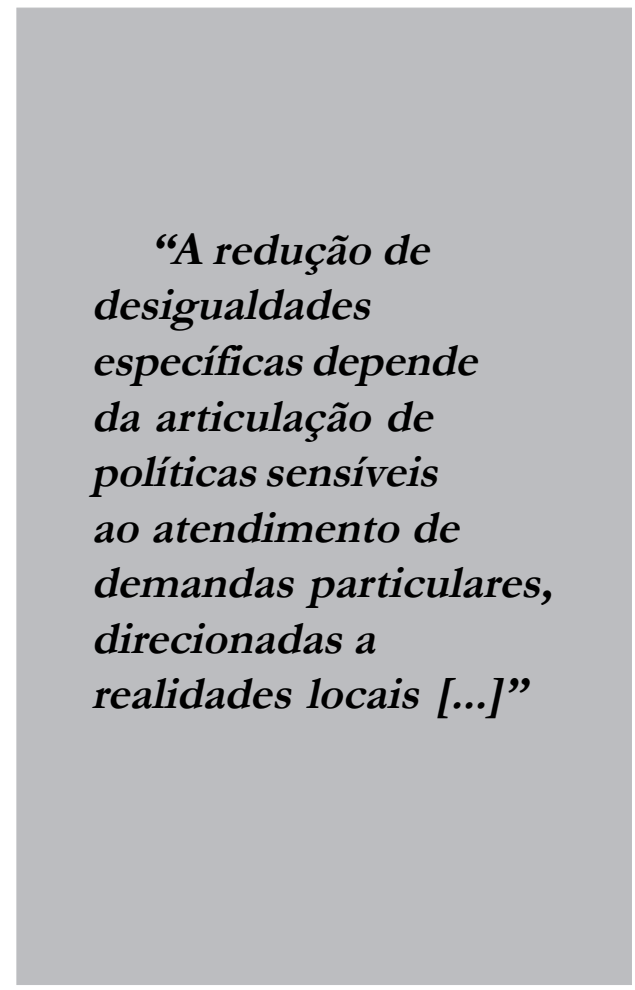

possibilitando sua seleção a partir de critérios objetivos, claros e transparentes. A seleção é feita entre as famílias que vivem em situação de pobreza e extrema pobreza, residentes em cada município. As situações de pobreza e extrema pobreza, para fins de concessão de benefício, são caracterizadas pela renda familiar mensal per capita de até $\mathrm{R} \$ 140,00$ e $\mathrm{R} \$ 70,00$, respectivamente. Contudo, a inclusão no Cadastro Único não gera direito 
subjetivo de concessão imediata de benefício no Programa Bolsa Família.

O Cadastro Único trata-se de uma base nacional que reúne os dados socioeconômicos das famílias com renda mensal de até meio salário mínimo per capita. O objetivo é registrar as famílias em situação de pobreza de todos os municípios brasileiros, que devem ser beneficiadas por programas sociais. As informações são coletadas pelas prefeituras municipais e permitem a identificação de potenciais beneficiários dos programas sociais. Ele é constituído dos seguintes grupos de informação: a) identificação do domicílio e de suas características; b) identificação da família; c) informações sobre os membros da família, relativas à documentação civil, escolaridade e qualificação profissional; d) renda da família; e) despesas mensais da família; f) informações sobre participação em programas sociais; e g) dados específicos para o agricultor familiar.
O PBF é composto por três dimensões, permeadas pelas lógicas da transversalidade e da intersetorialidade. A primeira refere-se ao alívio imediato da pobreza, por meio da transferência direta de renda às famílias pobres e extremamente pobres ${ }^{7}$. De acordo com a renda e o número de crianças e adolescentes entre 0 e 18 anos, as famílias conceituadas em situação de pobreza passam a receber por mês até $\mathrm{R} \$ 132,00$ e as famílias conceituadas em extrema pobreza, até $\mathrm{R} \$ 200,00$ - a estrutura dos benefícios está detalhada no Quadro $4^{8}$.

A segunda dimensão diz respeito ao reforço que o benefício visa oferecer para que direitos sociais básicos de saúde e educação sejam ofertados e acessados, contribuindo para que as famílias rompam o ciclo da pobreza perpetuado entre as gerações. Essa dimensão do programa se materializa por meio das chamadas condicionalidades - compromissos que as famílias devem cumprir para

\section{Quadro 4: Repercussão do Descumprimento das Condicionalidades do Progra- ma Bolsa Família - 2006/2007}

\begin{tabular}{|c|c|c|c|c|c|c|c|}
\hline & & \multicolumn{6}{|c|}{ Descumprimento / Sanções } \\
\hline \multirow{2}{*}{\multicolumn{2}{|c|}{ Períodos de Repercussão }} & Advertência & Bloqueio & $1^{\imath}$ Suspensão & $2^{a}$ Suspensão & Cancelamento & \\
\hline & & $\begin{array}{c}\text { sem efeito } \\
\text { sobre o } \\
\text { beneficio }\end{array}$ & $\begin{array}{c}\text { Bloqueio por } \\
30 \text { dias, } \\
\text { subsequente } \\
\text { desbloqueio }\end{array}$ & $\begin{array}{c}\text { Suspensão por } 60 \\
\text { dias, sem pagamento } \\
\text { das parcelas }\end{array}$ & $\begin{array}{c}\text { Suspensão por } 60 \\
\text { dias, sem pagamento } \\
\text { das parcelas }\end{array}$ & $\begin{array}{l}\text { Desligamento do } \\
\text { Programa }\end{array}$ & Total \\
\hline \multirow{3}{*}{ ڤั } & $\begin{array}{l}1^{\circ} \text { - Agosto } \\
\text { - educação: fev, mar e abr de } \\
2006 \\
\text { - saude: } 1^{2} \text { sem de } 2006\end{array}$ & 157.094 & 109 & 0 & 0 & 0 & 157.094 \\
\hline & $\begin{array}{l}2^{\circ} \text { - Setembro } \\
\text { - saude: } 1^{\circ} \text { sem de } 2006 \\
\text { (correção) }\end{array}$ & 15.174 & 110 & 0 & 0 & 0 & 15.393 \\
\hline & $\begin{array}{l}3^{\circ} \text { - Dezembro } \\
\text { - educação: mai, jun e jul de } \\
2006\end{array}$ & 201.717 & 56.288 & 48 & 0 & 0 & 258.053 \\
\hline \multirow{3}{*}{ స్ํำ } & $\begin{array}{l}4^{\circ} \text { - Março } \\
\text { - educação: ago e set de } 2006 \\
\text { - saude: } 2^{2} \text { sem de } 2006\end{array}$ & 216.811 & 82.014 & 29.891 & 25 & 0 & 328.741 \\
\hline & $\begin{array}{l}5^{\circ} \text { - Maio } \\
\text { - educação: out e nov de } 2006\end{array}$ & 149.337 & 56.466 & 28.545 & 11.815 & 11 & 246.174 \\
\hline & $\begin{array}{l}6^{2} \text { - Setembro } \\
\text { - educação: abr e mai de } 2007 \\
\text { - saúde: } 1^{\circ} \text { sem de } 2007\end{array}$ & 165.312 & 50.870 & 21.497 & 10.443 & 4.142 & 252.264 \\
\hline & Total & 905.445 & 245.857 & 79.981 & 22.283 & 4.153 & 1.257 .719 \\
\hline
\end{tabular}


permanecerem no programa, conforme explicado a seguir.

Uma vez incluídas no PBF, as famílias são estimuladas a manter crianças e adolescentes em idade escolar em instituições de ensino e a cumprir cuidados básicos de saúde - calendário de vacinação para crianças de 0 a 6 anos e agenda pré e pós-natal para gestantes e nutrizes. O descumprimento das condições acarreta consequências não apenas para as famílias, que podem ter o benefício cancelado, mas para os gestores municipais e instâncias de controle social que são, assim, alertados da existência de famílias em maior grau de vulnerabilidade e risco social. A frequência de crianças e adolescentes, em risco de trabalho infantil, a serviços socioeducacionais também se configura como condicionalidade do programa, em decorrência da integração do PBF com o Peti; mas o sistema de acompanhamento ainda está em fase piloto e por esse motivo o descumprimento do compromisso ainda não acarreta a perda do benefício.

O programa sustenta-se na lógica de que famílias com dificuldades de cumprimento da agenda social devem ser atendidas também por outras políticas intersetoriais específicas. Uma vez assistidas em outros aspectos da vida não contemplados pelas condicionalidades de saúde e educação, as famílias teriam condições de retomar a agenda do programa, garantir o recebimento do benefício e romper o ciclo da pobreza, em uma lógica circular?.

A terceira dimensão do PBF relacionase à articulação do governo federal com estados, municípios e entidades da sociedade civil, para ampliar e potencializar a oferta dos programas e ações complementares aos beneficiários. O objetivo é complementar e potencializar os impactos proporcionados pelas transferências condicionadas de renda na redução das desigualdades, promovendo um salto qualitativo que contribua não apenas para a melhor distribuição da renda, mas que conduza as famílias para uma situação de superação sustentada da vulnerabilidade econômica e social.

$\mathrm{Na}$ seção seguinte, é apresentada a estratégia de articulação de programas complementares ao PBF e suas potencialidades para contribuir no combate à desigualdade e promover a inclusão social.

\section{Articulação de programas e ações complementares, em 2006 e 2007}

O decreto que regulamenta o PBF (BRAsIL, 2004b) estabelece como objetivo básico do programa "estimular a emancipação sustentada das famílias que vivem em situação de pobreza e extrema pobreza" (art. $4^{\circ}$, inciso III). Nesse sentido, os programas complementares à transferência de renda, articulados em 2006 e 2007, visaram contribuir para o desenvolvimento das capacidades dos membros dessas famílias e para a oferta de oportunidades de trabalho e de geração de renda, a fim de possibilitar a superação da situação de pobreza e de vulnerabilidade social em que se encontravam. Esses programas se caracterizaram como ações organizadas e regulares, direcionadas às famílias pobres que recebem o benefício do Programa Bolsa Família ou àquelas inscritas no Cadastro Único.

Os programas complementares possibilitam o reconhecimento das necessidades de grupos populacionais em situação de risco social e a articulação de ações específicas para as suas necessidades. O desenvolvimento dos programas e de ações complementares está apoiado na premissa de que a realidade é complexa e 
que os problemas e as desigualdades sociais são fenômenos multidimensionais (Young, 1989). Essa lógica conceitual, presente na tese de Amartya Sen (1992) "Desigualdade Reexaminada”, estabelece que não se deve medir o bem-estar individual com base apenas em dimensões de renda e acesso a bens de consumo. Uma vida boa é a que permite ao indivíduo fazer suas próprias escolhas. Contudo, para que se possa escolher, é preciso que existam oportunidades reais, isto é, acesso a diferentes possibilidades e alternativas. O desenvolvimento das capacidades das famílias mais pobres seria uma forma de tornar esses indivíduos mais exigentes em relação a suas escolhas e torná-los mais capazes e qualificados para alcançar e manter seus objetivos.

Os programas complementares apresentam uma estratégia de longo prazo e uma de curto prazo. Na primeira, incluem-se as ações que produzem resultados e impactos de forma não imediata, por meio do desenvolvimento de capacidades dos membros das famílias, tanto as suas capacidades relativas ao labor quanto as de escolher os melhores rumos para a própria vida. O objetivo com esses programas é tornar os indivíduos mais aptos, mais qualificados e mais seguros quando oportunidades lhes forem oferecidas. Nessa estratégia, estão incluídos os programas de aumento da escolaridade, de melhoria das condições habitacionais, por meio da oferta de infraestrutura básica de moradia e de qualificação profissional. Para atender as necessidades de curto prazo das famílias e para complementar as ações não imediatas, também foram oferecidas oportunidades de inserção imediata no mercado de trabalho e de melhoria das condições de vida, a partir de ações como de geração de empregos e renda e de programas de microcrédito para alavancar pequenos empreendimentos já existentes. Como exemplos, houve a implantação, em vários municípios, de programas de qualificação de mão de obra para a inclusão em projetos de geração de trabalho e renda nos mais variados ramos, como corte e costura, artesanato, hortas comunitárias, estímulo ao empreendedorismo, construção de casas para famílias pobres e outros.

O enfrentamento da pobreza em seu caráter multidimensional, que apresente resultados que sejam significativos, requer uma estratégia que consiga alcançar a intersetorialidade e a transversalidade, com esforços integrados dos diferentes setores dos três níveis de governo e da sociedade civil, e que tenha a capacidade de incorporar temas, visões, públicos, problemas e objetivos às tarefas da organização que não se encaixam nas estruturas organizativas tradicionais verticais (Menicucci, 2006).

Para efetivar a estratégia de enfrentamento do quadro da desigualdade e da exclusão social, foi necessário haver articulação entre as diferentes esferas do governo e da sociedade, observado o nível de responsabilidades de cada um. Buscouse ainda ampliar o enfrentamento da exclusão social nos diferentes âmbitos em que se podem operar seus fatores, para diferentes coletivos de população altamente vulnerável, no sentido do conceito de Young (1989) sobre cidadania diferenciada.

Do ponto de vista de seu desenho, os programas complementares podem ser: 1) exclusivos, formulados especificamente para atender as pessoas inscritas no Cadastro Único e, em especial, as beneficiárias do PBF; ou 2) não exclusivos, compostos principalmente por programas já implementados para populações-alvo variadas, que passaram a focalizar ou a priorizar as famílias cadastradas no CadÚnico ou as beneficiárias do PBF. 
As informações contidas no Cadastro Único são poderosos elementos para a formulação de programas complementares, com dados sobre a escolaridade dos membros da família, seus rendimentos, as atividades econômicas que desempenham, participação em outros programas, endereço completo, a situação do domicílio, o tipo de domicílio e a infraestrutura. Os dados sobre o domicílio, por exemplo, contribuem para a formulação de políticas habitacionais direcionadas a populações específicas. As informações sobre a escolaridade de cada membro da família ajudam na formulação de políticas educacionais e na identificação das pessoas que demandam cursos de alfabetização e de capacitação de jovens e adultos.

A seguir, são apresentados os aspectos da intersetorialidade e da transversalidade da estratégia de articulação de programas complementares ao Bolsa Família, utilizada em 2006 e 2007, e de criação de um espaço propício para o surgimento e o desenvolvimento de inovações no campo das políticas sociais. Na primeira parte, é apresentada a característica intersetorial de ação adotada pelo governo federal, mais especificamente pela Secretaria Nacional de Renda para a Cidadania (Senarc/MDS), para a articulação desses programas complementares federais e a carteira de programas articulados por essa secretaria com outras pastas do governo durante o biênio. $\mathrm{Na}$ segunda parte, são apresentados o caráter transversal da articulação dos programas complementares, com a participação dos governos estaduais e municipais, e exemplos dessas ações.

\section{Estratégia intersetorial de ação}

A intersetorialidade é definida como "a articulação de saberes e experiências no planejamento, na realização e na avaliação de ações, com o objetivo de alcançar resultados integrados em situações complexas, visando a um efeito sinérgico no desenvolvimento social" (JunQUEIRA, 1997). O decreto que regulamenta o Bolsa Família (BRAsiL, 2004b) estabelece que os estados, os municípios e o Distrito Federal devem promover ações que viabilizem a gestão intersetorial (arts. 13 a 15). A estratégia intersetorial para a oferta de programas complementares para as famílias benefi-

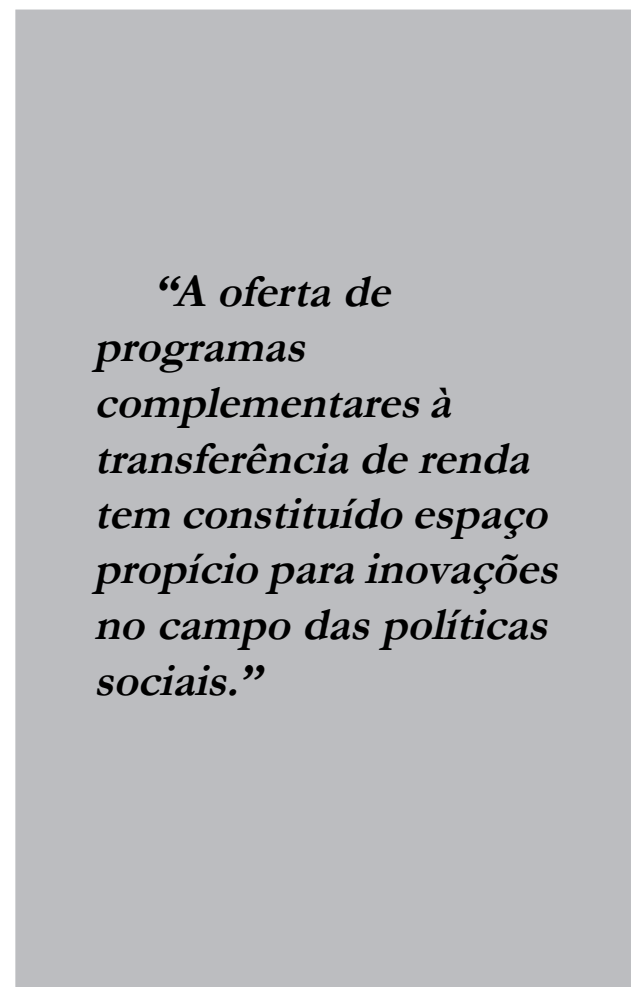

ciárias do PBF está materializada na realização de ações em diferentes âmbitos da desigualdade e da exclusão social.

Visando oferecer uma carteira de programas complementares mais coerente e focalizada nas necessidades das famílias inscritas no Cadastro Único, em 2006 e 2007, foi incentivada a realização de parcerias com outros ministérios que se enquadrassem em quatro das categorias do 
Índice do Desenvolvimento das Famílias (IDF): acesso ao conhecimento; acesso ao trabalho e renda; condições habitacionais e cidadania. O que motivou a atuação em torno desses quatro eixos foi a percepção pela Senarc/MDS de que eram os que apresentavam a maior capacidade de impacto sobre as famílias assistidas pelo PBF e sobre as inscritas no Cadastro Único.

O IDF surgiu da necessidade de se ter um indicador que, além de levar em consideração diversas dimensões da pobreza, como o Índice de Desenvolvimento Humano (IDH), pudesse ser construído para cada família e tivesse a capacidade de sintetizar suas características. Assim, o IDF permite calcular o nível de desenvolvimento de uma família e agregar dados sobre o grau de desenvolvimento de bairros, territórios, municípios, estados e países. Pode ser usado tanto em comparações individuais, entre famílias, quanto em nível agregado, entre regiões ou grupos demográficos (Barros, Carvalho \& Franco, 2006). O IDF é calculado pela Secretaria Nacional de Renda para a Cidadania (Senarc/MDS) e se baseia em informações de uma única fonte: o Cadastro Único. Isso significa que as variáveis do cadastro é que servem de referência para a construção do índice e que as comparações entre IDF de famílias diferentes só são viáveis entre as cadastradas. Esse índice trabalha com seis dimensões: vulnerabilidade decorrente da composição familiar ${ }^{10}$; acesso ao conhecimento ${ }^{11}$; acesso ao trabalho ${ }^{12}$; disponibilidade de recursos ${ }^{13}$; desenvolvimento infantil ${ }^{14}$; e condições habitacionais ${ }^{15}$.

Os nove programas complementares que foram articulados pela Senarc/MDS ao PBF em 2006 e 2007, relacionados no Quadro 5, eram programas que já estavam sendo implementados pelos respectivos ministérios executores antes da parceria firmada com o MDS. Esses programas complementares, após a parceria com a Senarc/MDS, passaram a ter como clientela prioritária as famílias beneficiárias do PBF ou o público potencial das famílias inscritas no Cadastro Único, conforme o que se demonstrava como o mais adequado para cada programa. Essas parcerias proporcionaram, para as famílias pobres e extremamente pobres, a oportunidade de serem incluídas em um amplo conjunto de serviços e políticas federais, satisfazendo as suas necessidades e considerando as suas características.

O estabelecimento de cooperações com o MDS também trouxe benefícios aos ministérios parceiros, como o acesso a informações e relatórios do Cadastro Único, que permitiu realizar melhores diagnósticos para suas próprias políticas e programas, planejá-las com maior nível de segurança e facilitar o seu monitoramento e avaliação. Outro benefício dessas parcerias era a possibilidade de localizar e contatar as pessoas pertencentes ao público-alvo dos programas que estivessem no CadÚnico. A terceira vantagem foi a oportunidade de contar, na implementação e no monitoramento do programa, com o apoio da infraestrutura institucional do Bolsa Família, em todos os municípios e estados brasileiros, do Sistema Único de Assistência Social (Suas) e de sua rede socioassistencial ${ }^{16}$, composta pelos Centros de Referência e Assistência Social $\left(\mathrm{CRAS}^{17}\right)$.

Em todas as nove articulações realizadas pela Senarc/MDS em 2006 e 2007, os gestores municipais, as instâncias de controle social (ICS) e os coordenadores estaduais do Bolsa Família foram mobilizados para que pudessem apoiar a divulgação local de cada programa, caso esse fosse oferecido em seu município ou estado, e no incentivo às famílias para a 
participação em cada programa, dependendo do perfil por ele requerido. Para isso, a Senarc/MDS contatava os gestores dos municípios, muitas vezes por meio de ofício ou de mensagem eletrônica em formato de mala direta, os informava a respeito das características do programa complementar e fornecia as orientações necessárias para a articulação local. Isso foi realizado, por exemplo, na fase de matrícula do programa Brasil Alfabetizado em 2007, tendo sido mobilizados gestores de cerca de 2.500 municípios; e para a inscrição no Cadastro Único de trabalhadores libertos de condições análogas à escravidão, pelas ações de fiscalização do Ministério do Trabalho e Emprego (MTE).
A seguir, são apresentadas as categorias que enquadram os programas complementares articulados na esfera federal, em 2006 e $2007 .{ }^{18}$

\section{Acesso ao conhecimento}

Os programas que oferecem acesso ao conhecimento para a população contribuem para a redução da exclusão educacional. Segundo dados do IBGE, 16,3 milhões de pessoas no Brasil eram analfabetas em dezembro de 2006, ou seja, cerca de $12 \%$ da população. Entre os responsáveis legais beneficiados pelo $\mathrm{PBF}$, segundo dados do Cadastro Único de 2007, 42,98\% possuíam até a $4^{a}$ série do ensino fundamental. Nesse contexto, é

\section{Quadro 5: Programas complementares ao PBF articulados no âmbito federal, em 2006 e 2007}

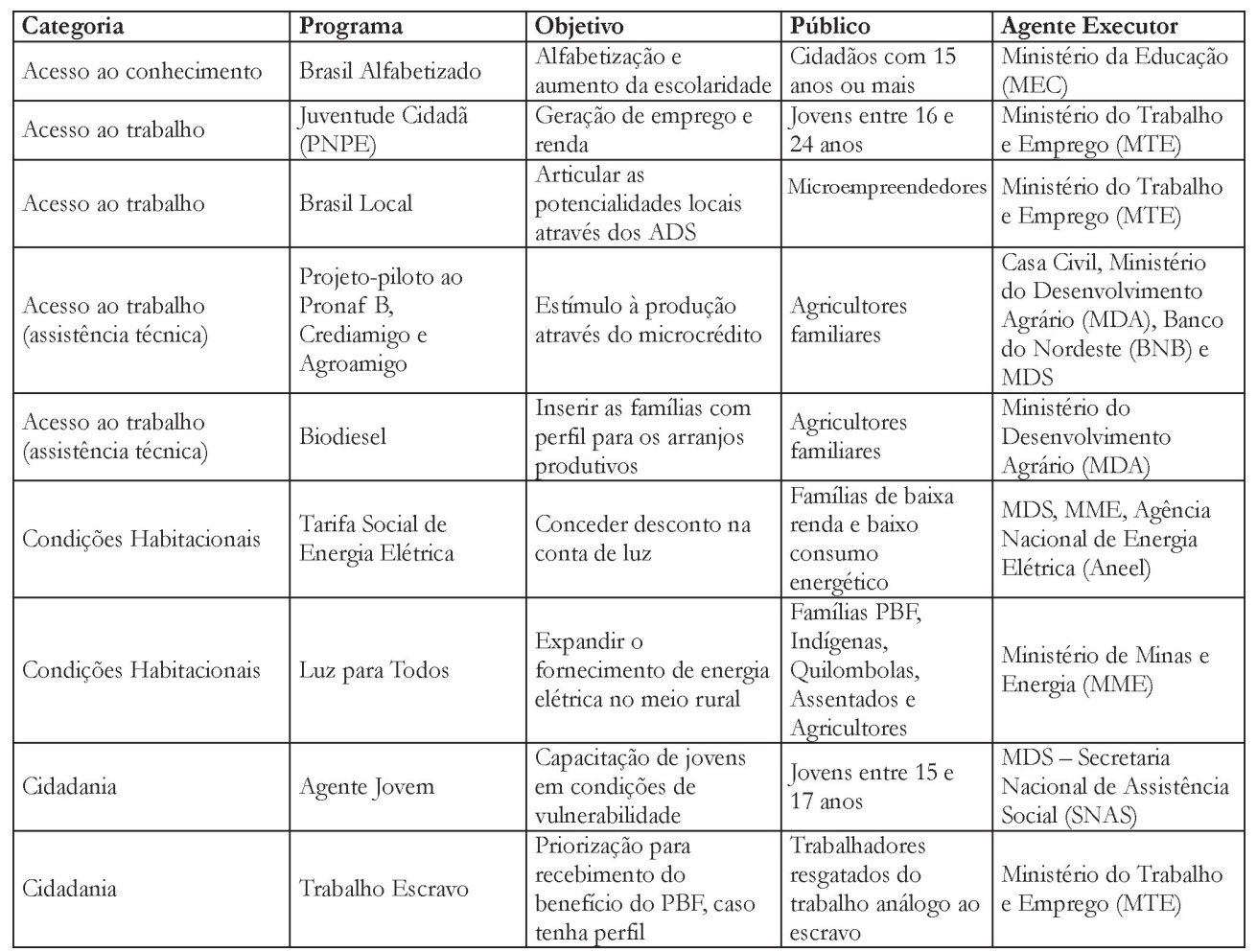


prioritária a articulação de programas que contribuam para o aumento da escolaridade e o acesso ao conhecimento por parte das familias de baixa renda.

O Brasil Alfabetizado (PBA) é um exemplo de programa articulado ao PBF, visando empreender esforços a fim de ofertar aos beneficiários do Bolsa Família uma ação complementar à transferência de renda para o aumento da escolaridade e a redução do analfabetismo, além de promover a sinergia das ações do poder público no combate à pobreza e à exclusão social. Esse programa teve a adesão de 3.894 municípios em 2006 e potencializou suas ações nos 1.000 municípios brasileiros com maiores índices de analfabetismo no ano de 2007. Nesses dois anos, mais de dois milhões de pessoas foram atendidas pelas turmas de alfabetização.

A articulação entre o PBA e o PBF tem como foco a localização de pessoas com perfil para alfabetização, inscritas no CadÚnico e beneficiárias do Programa Bolsa Família; a mobilização e sensibilização de gestores locais, instâncias de controle social, coordenadores estaduais do PBF e gestores locais do PBA para promoverem a inscrição desses cidadãos no programa; e o monitoramento e a avaliação conjunta das ações e dos resultados da cooperação.

Em 2006 e 2007, o MDS mobilizou gestores do Programa Bolsa Família e as instâncias de controle social em quase 1.500 municípios (incluindo os 1.000 municípios com mais alto índice de alfabetização), para a matrícula de analfabetos beneficiários do Bolsa Família e cadastrados no CadÚnico - que totalizam, segundo relatório do PBF, mais de 11 milhões de indivíduos. Essa ação resultou na matrícula de 442 mil pessoas inscritas no CadÚnico em turmas de alfabetização, das quais 334 mil eram beneficiárias do PBF.

\section{Acesso ao trabalho e renda}

A oferta de ações de trabalho e renda contribui tanto para a redução da exclusão laboral como da exclusão econômica. São programas e ações que dialogam com diferentes estratégias de políticas setoriais (agricultura familiar, desenvolvimento regional e local, economia solidária, empregabilidade etc.) e consideram a especificidade do público a ser atendido e as experiências histórica e territorial diferenciadas do local onde serão implementados. As ações articuladas nessa área em 2006 e 2007 foram: Juventude Cidadã e Brasil Local, executadas pelo Ministério do Trabalho e Emprego (MTE); o projeto piloto do Programa Nacional de Fortalecimento da Agricultura Familiar (Pronaf), executado pelo Ministério do Desenvolvimento Agrário (MDA) e associado aos programas de microcrédito do Banco do Nordeste do Brasil; e o Programa Nacional Biodiesel, executado também pelo MDA.

O Brasil Local (antigo Projeto de Promoção do Desenvolvimento Local e Economia Solidária), em articulação com o PBF, tem o objetivo de fomentar o desenvolvimento local sustentável como uma possibilidade de inclusão produtiva de famílias pobres no mercado de trabalho, em complementaridade à política de transferência de renda. Esse projeto busca promover ações de apoio ao desenvolvimento local, a partir da organização de empreendimentos coletivos solidários. No ano de 2006, o projeto incorporou 636 empreendimentos, totalizando 42.649 associados, e resultou no aumento de empresas legalizadas (com Cadastro Nacional de Pessoa Jurídica - CNPJ) e em benefícios institucionais, sociais, administrativos, produtivos e financeiros (FUNDAÇÃO UnIVERsidade DE Brasília, 2007). 


\section{Condições habitacionais}

Para a diminuição da exclusão sóciosanitária ou urbano-territorial, são necessárias ações que envolvam a possibilidade de acesso à propriedade de imóvel, à água, ao esgoto sanitário, à coleta de lixo, à eletricidade e à pavimentação, entre outros. As ações articuladas nesse campo foram o Programa Luz Para Todos e o Programa Tarifa Social, ambos em parceria com o Ministério de Minas e Energia (MME).

O Programa Tarifa Social de Energia Elétrica concede descontos de até $65 \%$ na conta de luz às famílias que apresentem baixo consumo de energia elétrica estejam inscritas no Cadastro Único e atendam às condições que as habilitem a ser beneficiárias do Programa Bolsa Família, de acordo com a resolução normativa, $\mathrm{n}^{\circ} 253$, de 14 de fevereiro de 2007, da Agência Nacional de Energia Elétrica. Há um esforço, tanto para incluir os cidadãos com esse perfil no Programa Tarifa Social quanto para inscrever os beneficiários desse programa no Cadastro Único.

\section{Cidadania}

Os programas associados ao exercício dos direitos civis e políticos dos cidadãos e aos serviços de proteção básica de assistência social visam à redução da exclusão política e da cidadania. São ações que promovem o fortalecimento da cidadania, incentivam o protagonismo e a participação política nos processos decisórios, o empoderamento das famílias, o fortalecimento de vínculos familiares e comunitários e a consciência dos direitos individuais e coletivos. Nesse âmbito, foram articulados os programas Agente Jovem, em parceria com a Secretaria Nacional de Assistência Social do MDS, e o de ação de combate ao trabalho escravo, em parceria com o Ministério do Trabalho e Emprego (MTE).
A ação de combate ao trabalho escravo, em articulação com o PBF, visa desenvolver ações de reinserção e promoção social dos cidadãos libertados do trabalho escravo em território brasileiro, por meio de sua inscrição no CadÚnico e no PBF, caso apresentem o perfil para participação no programa. Em 2007, 1.453 trabalhadores resgatados, que já estavam no CadÚnico, foram inseridos no PBF. Com relação aos registros dos trabalhadores não inscritos no CadÚnico, foram encaminhadas instruções aos municípios de origem quanto à necessidade de cadastramento desses cidadãos.

\section{Estratégia transversal de ação}

A gestão do PBF é uma responsabilidade compartilhada pelo governo federal, estados, Distrito Federal e municípios, cabendo a todos esses atores, entre outras ações, a formulação e implementação de programas complementares às famílias beneficiárias do PBF. De acordo com o decreto que regulamenta o programa (BRAsIL, 2004b), cabe aos estados "estimular os municípios para o estabelecimento de parcerias com órgãos e instituições municipais, estaduais, federais, governamentais e não governamentais, para a oferta dos programas sociais complementares" (art. 13, inciso VII); e cabe aos municípios "estabelecer parcerias com órgãos e instituições municipais, estaduais e federais, governamentais e não governamentais, para oferta de programas sociais complementares (art. 14, inciso VII). A cooperação de todos os níveis do governo na implementação de políticas sociais para a superação da pobreza é fundamental, tendo em vista que é no plano de cada território, com suas limitações e potencialidades, que os programas complementares podem encontrar sua escala adequada de formulação e implementação. 
A articulação de programas complementares ao PBF apresenta, portanto, uma lógica transversal, na medida em que os programas complementares são constituídos por atividades integradas, reunindo as diferentes esferas de governo e interrelacionando iniciativas que desenvolvem as capacidades das famílias pobres, com vistas a apoiá-las na busca de alternativas próprias de sustentação. Trata-se de programas criados por diferentes níveis de governo, que se combinam para ampliar os resultados de sua ação.

A oferta de programas complementares à transferência de renda é uma realidade nos níveis municipal e estadual e tem constituído espaço propício para inovações no campo das políticas sociais, tais como: o reconhecimento de demandas de subconjuntos populacionais cada vez mais específicos; a forma como essas subpopulações são envolvidas na formulação e na implementação desses programas; a grande diversidade de temas que têm sido abordados para o enfrentamento da desigualdade e da exclusão social em seus mais variados âmbitos; e a inclusão de instrumentos para o monitoramento e avaliação de resultados no desenho de alguns dos programas. O Quadro 6 lista alguns dos cerca de 150 programas complementares municipais e estaduais que estavam publicados, em abril de 2009, no Observatório de Boas Práticas na Gestão do $\mathrm{PBF}^{19}$, e permite perceber a presença dessas características supramencionadas.

As prefeituras têm financiado a implantação de programas complementares com recursos próprios e com recursos transferidos pelo governo federal. Uma pesquisa do Ministério do Desenvolvimento Social e Combate à Fome, realizada em 2007, sobre a utilização dos recursos federais transferidos aos municípios sob a forma do Índice de Gestão Descentralizada (IGD) ${ }^{20}$, apontou que 61\% dos 2.633 municípios que responderam ao instrumento enviado pelo MDS desenvolvem ações complementares destinadas aos beneficiários do PBF com esse recurso repassado pelo governo federal para aprimorar a gestão do Programa Bolsa Família. Essas ações consistiram em atividades de acesso ao microcrédito produtivo orientado, geração de trabalho e renda, cursos de capacitação, alfabetização de adultos, entre outras.

Uma análise das experiências de gestão do Bolsa Família enviadas pelos governos municipais e estaduais e publicadas no Observatório de Boas Práticas nos permite realizar algumas constatações interessantes, como o elevado interesse por parte dos municípios e estados na articulação de programas complementares e o fato de que isso está muito presente na gestão local do programa. Das 692 práticas inscritas de março a setembro de 2008, 264 correspondem à categoria de articulação de programas complementares $(38 \%$ do total). Entre as oito categorias de inscrição de práticas, essa foi a que teve mais experiências inscritas e publicadas. Entre as 26 experiências premiadas de todas as que foram publicadas no observatório de Boas Práticas, sete são de programas complementares. Outra constatação é que há um largo predomínio de ações de programas complementares implementadas pelos governos municipais em comparação com os governos estaduais. Foram 122 boas práticas municipais de gestão do PBF (de um total de 342 municipais), e seis práticas estaduais (para 27 práticas estaduais publicadas). Verifica-se ainda a existência de uma diversidade muito grande em termos do escopo dos programas 
Quadro 6: Amostra de programas complementares articulados pelos governos estaduais e municipais, publicados no Observatório de Boas Práticas, em Abril de 2009

\begin{tabular}{|c|c|c|}
\hline Título & $\begin{array}{c}\text { Ano de } \\
\text { publicação }\end{array}$ & Natureza \\
\hline Acesso a microcrédito para famílias beneficiárias do PBF & 2008 & Estadual \\
\hline Ações socioeducativas do Programa Bolsa Família & 2008 & Municipal \\
\hline Alfabetização de jovens e adultos & 2008 & Municipal \\
\hline $\begin{array}{l}\text { Aprender a aprender e apreender para construção } \\
\text { da cidadania }\end{array}$ & 2009 & Municipal \\
\hline Ateliê da família & 2008 & Municipal \\
\hline Bom de Bola: educando pelo esporte & 2009 & Municipal \\
\hline $\begin{array}{l}\text { Capacitar para incluir: construção civil gerando } \\
\text { emprego e renda }\end{array}$ & 2009 & Municipal \\
\hline Comunidade e paz é você quem faz & 2009 & Municipal \\
\hline Cozinhando com a energia solar & 2008 & Estadual \\
\hline Cozinhas comunitárias - Unidades I e II & 2008 & Municipal \\
\hline CRAS itinerante & 2009 & Municipal \\
\hline Cultivo de tilápias em tanques-redes & 2008 & Municipal \\
\hline Educação financeira cidadã para empreendimentos solidários & 2009 & Municipal \\
\hline Escola Móvel de Inclusão Digital - Caminhão Digital & 2008 & Estadual \\
\hline Fundo Carioca & 2008 & Municipal \\
\hline Geração de emprego e renda - Araxá (MG) & 2008 & Municipal \\
\hline Gerando oportunidades de inclusão social & 2009 & Municipal \\
\hline Grupo de Salgadinhos Básicos & 2009 & Municipal \\
\hline Horta Familiar: cultive uma horta e colha qualidade de vida & 2008 & Municipal \\
\hline Inclusão social com hortas comunitárias & 2009 & Municipal \\
\hline $\begin{array}{l}\text { Iogurte de leite de cabra produzido por assoc. de } \\
\text { Mulheres do PBF }\end{array}$ & 2009 & Municipal \\
\hline Kerubim Net - programa de inclusão digital & 2008 & Municipal \\
\hline Monitoramento e acompanhamento social & 2009 & Municipal \\
\hline Mulheres Chefes de Família - Dona Lindu & 2009 & Municipal \\
\hline Oficina sócio-terapêutica e comunitária de costura & 2009 & Municipal \\
\hline Padaria Comunitária Xakriabá & 2009 & Municipal \\
\hline Participação e ação para nossa inclusão & 2008 & Municipal \\
\hline PENARUA - Programa Empreendedorismo na Rua & 2008 & Municipal \\
\hline Produção solidária - Incentivo à criação de cooperativas & 2006 & Municipal \\
\hline Programa Bolsa Trabalho & 2008 & Estadual \\
\hline Projeto Acordes da Vida & 2008 & Municipal \\
\hline Projeto Cavalgar & 2009 & Municipal \\
\hline Projeto de Segurança Alimentar e Nutricional & 2009 & Municipal \\
\hline $\begin{array}{l}\text { Projeto técnicas de manejo em cana de açúcar e } \\
\text { preparo do álcool }\end{array}$ & 2008 & Municipal \\
\hline Propen - Programa Porta de Entrada & 2008 & Municipal \\
\hline $\begin{array}{l}\text { Qualificação profissional em tecnologia de } \\
\text { sistemas de segurança }\end{array}$ & 2008 & Municipal \\
\hline Salão de beleza popular & 2008 & Municipal \\
\hline $\begin{array}{l}\text { Utilização do CadÚnico para famílias para política } \\
\text { habitacional }\end{array}$ & 2009 & Municipal \\
\hline
\end{tabular}


complementares, com temas de cidadania, incentivo a energias alternativas, produção local, inclusão digital, vinculação de política habitacional à seleção de famílias no Cadastro Único sem moradia adequada, padarias comunitárias, construção de jardins, hortas comunitárias e questões de gênero. Programas que visam à redução da exclusão laboral e econômica aparecem com maior frequência, com ações na área da qualificação profissional e da geração de trabalho e renda que envolvem o acesso ao crédito, o estímulo ao associativismo e ao cooperativismo e parcerias com o setor privado para absorção de mão de obra qualificada.

Apesar de os governos estaduais estarem menos mobilizados nesse processo, há vários casos de programas complementares estaduais, e o envolvimento desses é muito importante para o enfrentamento da desigualdade e da exclusão social. O Programa Bolsa Trabalho, por exemplo, é um programa estadual complementar ao PBF executado pela Secretaria de Estado de Trabalho, Emprego e Renda do Pará, que visa à qualificação profissional e à concessão de crédito para micro e pequenos negócios. Esse programa tem o objetivo de proporcionar oportunidades de emprego, trabalho e renda a jovens residentes há mais de três anos no estado, com idade entre 18 e 29 anos, pertencentes a famílias beneficiárias do PBF e que tenham mais de cinco anos de estudo. Os participantes recebem benefício no valor de $\mathrm{R} \$ 70,00$ por mês, condicionado à participação nas atividades de qualificação profissional e em reuniões trimestrais.

Um importante ator na articulação de programas complementares nos municípios é o Centro de Referência de
Assistência Social (CRAS), espaço de referência da proteção social básica e "porta de entrada" dos usuários à rede socioassistencial. $\mathrm{Na}$ execução das atividades de acompanhamento das famílias, a equipe do CRAS realiza um diagnóstico da realidade local, por meio de entrevistas com as famílias, visitas domiciliares e grupos de acompanhamento, e levanta as situações de vulnerabilidade social que podem afetar os vínculos familiares e comunitários. Nas atividades desenvolvidas pelo CRAS, são colhidas informações sobre as vivências de cada família, seus valores, crenças e particularidades, e dados sobre a cultura da comunidade, que podem servir para a adequação da oferta de serviços sociais na localidade às suas necessidades e para encaminhá-las às ações e programas complementares desenvolvidos pela prefeitura.

\section{Considerações finais}

O combate à desigualdade e à pobreza e o apoio às famílias marginalizadas têm constado da agenda social de muitos países em todo o mundo na última década, desde as nações do chamado Estado do bem-estar social aos países de renda baixa. As políticas mais expandidas em todo o mundo, na última década, para combater esses problemas têm sido os programas de transferência direta de renda às famílias em situação de pobreza, os quais apresentam muitas diferenças entre si e contam com recursos e cobertura populacional crescentes.

No Brasil, as políticas de transferência de renda têm-se mostrado bastante eficazes, contribuindo para a redução da desigualdade econômica. Entretanto, o fenômeno da desigualdade social costuma ser analisado e enfrentado predominantemente sob uma perspectiva econômica, deixando de ser 
abordadas outras de suas dimensões, como as desigualdades educacionais, sanitárias, de gênero, de raça, a "ausência de autoestima, de reconhecimento social, de aprendizado familiar de papéis sociais básicos", entre outras (SouZA, 2006).

O PBF constitui uma política que, ao agir em três dimensões - transferência direta de renda; cumprimento de condicionalidades de educação, saúde e assistência social; e a articulação de ações e programas complementares - e focalizar sua intervenção nas famílias pobres e extremamente pobres e em subextratos dessas populações, tem a capacidade de impactar em vários aspectos da exclusão social desses cidadãos, de reduzir seus diferentes níveis de desigualdade e de combater muitos dos fatores determinantes da pobreza. A expectativa é que os programas e as ações complementares, juntamente com o cumprimento das condicionalidades de saúde e educação, produzam impactos adicionais à transferência de renda, na quebra do ciclo de transmissão da pobreza entre gerações; que reconheçam necessidades de subgrupos populacionais; que reduzam as desigualdades socioeconômicas; e contribuam para a emancipação dos beneficiários do Bolsa Família sob uma perspectiva de longo prazo.

Entre os principais elementos que diferenciam o PBF frente a outros programas de transferência direta de renda do Brasil e do exterior, destacam-se: 1) o caráter descentralizado da execução e da gestão do programa, em que os governos municipais são os responsáveis, entre outras atribuições, pela localização, cadastramento e acompanhamento das famílias pobres que acessam os sistemas de informação do programa, contando com todos os dados relativos ao cadastro das famílias, à concessão dos benefícios financeiros e ao cumprimento das condicionalidades; 2) o fato de haver gestores em todos os municípios brasileiros e no Distrito Federal, e coordenadores em todos os estados da federação, que usualmente estão relacionados às secretarias municipais e estaduais de Assistência Social e ao Sistema Único de Assistência Social (Suas), o que constitui uma rede capilarizada e fortemente associada com os atores-chave das políticas de assistência social no Brasil; 3) a oferta de ações e programas complementares aos beneficiários das transferências de renda, com a expectativa de contribuir para a redução da desigualdade e da exclusão social em âmbitos específicos da vida das famílias em situação de pobreza; e 4) a existência de uma instância de controle social do programa em cada município, com representação paritária da sociedade civil, pleno acesso às informações do PBF no nível municipal e atribuições consultivas, que têm como objetivo acompanhar a execução e auxiliar na fiscalização da gestão do programa.

A articulação de programas e ações complementares à transferência de renda tem constado da agenda das políticas sociais nos três níveis de governo, de maneira mais intensa no âmbito federal e municipal, provavelmente em função das características do Programa Bolsa Família, que estabelece mais responsabilidades para os gestores desses níveis de governo do que para os estaduais. Os programas complementares têm criado um ambiente propício ao surgimento de ações, programas e políticas de combate à pobreza, alguns desses com características inovadoras no campo das políticas sociais.

$\mathrm{O}$ aspecto da transversalidade na articulação de programas complementares está presente sob duas formas. A primeira, pela concepção e oferta desses programas pelos 
três níveis de governo, obedecendo às prioridades e às percepções de cada ente federativo em sua área de responsabilidade, conforme os exemplos já citados. A segunda pode ser percebida principalmente no caso dos programas complementares federais, ao contarem com os gestores municipais do PBF e com seus coordenadores estaduais para apoiarem o nível federal em tarefas como a divulgação dessas ações, a localização de potenciais beneficiários de programas em específico, a mobilização do público-alvo beneficiário e em outras ações.

A intersetorialidade também está muito presente na articulação dos programas e ações complementares. A promoção de programas em diferentes âmbitos da exclusão social, nas condições de vulnerabilidade como as citadas por Brugué (2002) para o conceito de cidadania diferenciada, ampliou a capacidade do Estado de atender às necessidades das familias em situação de pobreza. Além disso, a gestão intersetorial das ações complementares, incentivada pelo decreto de criação do PBF (BRASIL, 2004b), permitiu dar continuidade ao processo de desenvolvimento das famílias pobres e extremamente pobres com, por exemplo, a associação de ações de assistência técnica a pequenos empreendimentos e a programas de microcrédito, o que tornou mais provável o sucesso do empreendimento atendido.

Uma condição necessária para a intersetorialidade e para a transversalidade na articulação de programas complementares é o caráter descentralizado da gestão do programa. O município é responsável por aspectos fundamentais do PBF, tais como o cadastramento das famílias, as visitas domiciliares e o monitoramento do cumprimento das condicionalidades, e tem amplo acesso aos sistemas de informação do PBF e ao CadÚnico.
A disponibilidade de informações e a sensibilização e qualificação desses atores à oferta de programas complementares à transferência de renda, em seu nível de abrangência e responsabilidade, foram fatores que incentivaram os governos municipais e estaduais a ofertarem suas próprias ações e a participarem das articulações federais. Os governos municipais e estaduais possuem o acesso aos sistemas de informação do programa, contando com todos os dados relativos ao cadastro das famílias (Cadastro Único de Programas Sociais), à concessão dos benefícios financeiros (Sistema de Benefício ao Cidadão) e ao cumprimento das condicionalidades (Sistema de Condicionalidades).

Os governos locais, em função de sua proximidade e envolvimento com a população, possuem maior capacidade de identificação das necessidades, de planejamento e de execução das políticas sociais. A gestão local torna as ações relativas à articulação de programas complementares mais efetivas, beneficiando contingentes populacionais mais homogêneos, identificados a partir de informações das famílias inscritas no Cadastro Único. Entre os ganhos obtidos, foi possível verificar a valorização do saber local e da identidade dos atores envolvidos, para a flexibilidade e adaptação das políticas públicas às realidades específicas e para o estabelecimento de parcerias com entidades locais do setor privado.

A institucionalização da participação popular, por meio das instâncias de controle social e por meio de canais de comunicação e publicidade da ação pública, fez surgir espaços públicos de representação e negociação, contribuindo para que as demandas por ações complementares sejam transmitidas aos gestores do programa e para que as ações em implementação sejam 
divulgadas à sociedade. Esses espaços permitem que os gestores recebam essas demandas, negociem-nas e trabalhem de forma a atendê-las, implantando ações de interesse da população.

É importante ressaltar que não se tem a pretensão de que a articulação de programas e ações complementares seja a única e tampouco a principal estratégia de combate à desigualdade e à exclusão social no Brasil. A desigualdade decorre de relações de dominação e exploração socioeconômica que são estruturais e politicamente referendadas e que se alimentam da exclusão social, impossibilitam o acesso a bens materiais e culturais produzidos pela sociedade e inviabilizam a participação de certos segmentos da sociedade no comando do espaço público.

Além disso, ainda não foi possível medir o impacto dos programas e ações complementares na redução das desigualdades nos âmbitos da exclusão social, identificados por Young (1989), tais como a laboral, educativa, sócio-sanitária, urbanoterritorial e outras. Embora o PBF contribua para a redução da pobreza no Brasil, conforme demonstra recente estudo do Ipea $^{21}$, sua eficácia para a redução de desigualdades em outras esferas ainda precisa ser mais bem dimensionada. Há dificuldades metodológicas para a avaliação do impacto desses programas em virtude da dificuldade de isolar os fatores intervenientes sobre as famílias beneficiárias do Programa Bolsa Família, entre as que participaram dos programas.

Apesar do caráter recente dos programas complementares e das dificuldades de monitoramento em cada um, tanto por questões metodológicas quanto pelo deficiente acompanhamento realizado pelos ministérios responsáveis, os resultados obtidos têm sido bastante animadores e sugerem avaliações mais robustas no futuro.

Os resultados verificados com os programas complementares federais; o elevado comprometimento dos governos municipais e estaduais na articulação de programas próprios; as possibilidades que os programas complementares oferecem no enfrentamento dos múltiplos aspectos em que operam os fatores de exclusão social e a disponibilidade de instrumentos adequados para a articulação de programas, como o Cadastro Único, são elementos que permitem vislumbrar a articulação desses programas como mais uma opção na agenda das políticas sociais dos três níveis de governo no Brasil, sobretudo quando se trabalha dentro de uma estratégia de focalização de política.

(Artigo recebido em julho de 2009. Versão final em março de 2010).

\section{Notas}

1 Coeficiente de Gini - medida do grau de concentração da distribuição de renda de uma população, cujo valor varia de zero (perfeita igualdade) até um (a desigualdade máxima).

2 O elemento estrutural significa que é decorrente da industrialização e do processo de acumulação de capital. A dinamicidade consiste em que as fronteiras da exclusão são móveis e fluidas; os índices de risco apresentam extensões sociais e intensidades pessoais altamente mutáveis. A multifatorialidade desse problema requer abordagens integrais em sua definição e horizontais em seus processos de gestão. A dimensão politizável significa que o coletivo pode se auto-organizar e ser 
o portador de um novo modelo alternativo com potencial de superação das relações de desigualdade vigentes (BRUGUÉ, 2002).

3 Young (1989) in Fleury (2004a) considera que a igualdade requer a afirmação de diferenças grupais, e sugere como formato para a cidadania diferenciada a criação de fundos públicos para prover formas de defesa e garantia de representação de grupos oprimidos e a existência de políticas diferenciadas para atender às demandas singulares desses grupos.

4 As políticas de integração buscavam grandes equilíbrios, pela homogeneização da sociedade a partir do centro, com vistas a promover o acesso de todos. As políticas de inserção, que nasceram oficialmente nos anos 1980, seguem a lógica de discriminação positiva: definem com precisão a clientela e as zonas singulares do espaço social e desenvolvem estratégias específicas para elas. São entendidas como iniciativas de reequilíbrio para recuperar distância.

5 É um programa de transferência direta de renda do governo federal para famílias que possuem crianças e adolescentes, na faixa etária dos 7 aos 15 anos de idade, envolvidos no trabalho precoce, considerado perigoso, penoso, insalubre ou degradante. Para isso, o Peti concede uma bolsa às famílias desses jovens em substituição à renda que traziam para casa. Em contrapartida, as famílias têm que matricular seus filhos na escola e fazê-los frequentar a jornada ampliada. Essas atividades foram regulamentadas pela Portaria n ${ }^{\circ} 20$, de 13/9/2001, da Secretaria de Inspeção do Trabalho, do Ministério do Trabalho e Emprego.

6 O Programa Agente Jovem tem como público-alvo jovens de 15 a 17 anos em situação de vulnerabilidade e risco social, que fazem parte de famílias com renda per capita de até $1 / 2$ salário mínimo. Visa proporcionar experiências práticas mantendo a sua permanência no sistema educacional e com a finalidade de inseri-lo no mundo do trabalho. O programa prioriza o atendimento a jovens egressos de programas sociais, como o Peti; que estejam fora da escola; oriundos de programas de atendimento a situações de exploração sexual; e o que estejam sob medida de proteção, aos quais se atribui o cometimento de atos infracionais (egressos ou em liberdade assistida).

7 Em 2007, o PBF considerava extremamente pobres as famílias com renda mensal de até $\mathrm{R} \$ 60,00$ per capita. Já as famílias pobres eram aquelas com renda mensal entre $\mathrm{R} \$ 60,01$ e $\mathrm{R} \$ 120,00$ per capita.

8 O cadastramento das famílias é realizado pelo município, mais especificamente pelo órgão gestor do programa, indicado pelo prefeito no ato da adesão. Na maioria das vezes, trata-se da Secretaria Municipal de Assistência Social.

9 Há um esforço para que as famílias incorporem a dimensão do cumprimento das condicionalidades na perspectiva de um direito e não de um dever.

${ }^{10}$ Volume adicional de recursos que a família necessita pelo fato de possuir, em sua composição, gestantes, crianças, portadores de deficiência e idosos.

11 Acesso à alfabetização, escolaridade ou qualificação profissional que, por sua vez, possibilita o acesso a recursos financeiros (via mercado de trabalho) e não financeiros (bens e serviços públicos).

12 Condições de utilização da capacidade produtiva como fonte de renda, considerando a disponibilidade de trabalho (tempo na ocupação), a qualidade do posto de trabalho (formal ou informal) e a remuneração obtida com o trabalho (em relação ao salário mínimo).

${ }^{13}$ Condições de obtenção de renda para cada membro do grupo familiar e sua sustentabilidade (mercado de trabalho ou transferências).

14 Acesso a oportunidades para o pleno desenvolvimento das capacidades e potencialidades de cada criança. Abrange aspectos como a proteção contra o trabalho precoce, o acesso à escola, o progresso escolar e a mortalidade infantil.

${ }^{15}$ Condições de vida de uma família, incluindo propriedade de imóvel, acesso à água, ao esgoto sanitário, à coleta de lixo e à eletricidade. 
16 A rede socioassistencial é constituída pela rede de assistência social, juntamente com as redes de saúde, educação, cultura, habitação, e outras. O conceito de rede socioassistencial pressupõe a articulação das ações que se voltam ao destinatário da política de assistência social.

17 O CRAS, também conhecido como "Casa das Famílias", é uma unidade pública estatal localizada estrategicamente em áreas de maior vulnerabilidade social do município, que presta serviços de proteção social àqueles que a procuram e buscam atendimento social. O objetivo das atividades do CRAS é prevenir o risco social, fortalecendo os vínculos familiares comunitários e promovendo a inclusão das famílias nas políticas públicas, no mercado de trabalho e na vida em comunidade.

18 Informações sobre os programas complementares articulados em nível federal pela Senarc/ MDS estão disponíveis no sítio do Ministério do Desenvolvimento Social e Combate à Fome, no endereço http://www.mds.gov.br/bolsafamilia/programas_complementares.

19 O Observatório de Boas Práticas na Gestão do Programa Bolsa Família (PBF) é um espaço virtual no sítio do MDS que identifica, reúne e divulga as boas práticas na gestão do PBF, desenvolvidas elos estados e municípios, e apoia a constituição de uma rede de gestores que atuam na implementação e no acompanhamento do programa. Nesse ambiente virtual, podem ser conhecidas as ações desenvolvidas pelos municípios e estados em oito aspectos do PBF: gestão integrada do Bolsa Família, cadastramento de famílias, gestão de benefícios, gestão de condicionalidades, fiscalização, controle social, articulação de programas complementares e acompanhamento familiar. A publicação das práticas representa o reconhecimento do MDS de que aquela experiência local de gestão do programa atingiu os objetivos de contribuir para a redução da pobreza e para a promoção e proteção social das famílias mais pobres. Para acessar o Observatório, digite: http://www.mds.gov.br/bolsafamilia/observatorio.

${ }^{20}$ O Índice de Gestão Descentralizada (IGD) foi criado em 2006 e é um número indicador que varia de 0 a 1 e mostra a qualidade da gestão do Programa Bolsa Família (PBF) no âmbito municipal. Quanto maior o valor do IGD, maior o recurso transferido ao município, que visa incentivar o aprimoramento da qualidade da gestão do PBF em âmbito local, e contribuir para que os municípios executem as ações que estão sob sua responsabilidade. O IGD é calculado pela média aritmética das seguintes variáveis: qualidade e integridade das informações constantes no CadÚnico (taxa de cobertura de cadastros); taxa de atualização de cadastros; taxa de crianças com informações de frequência escolar; e taxa de famílias com acompanhamento das condicionalidades de saúde.

21 Sobre a recente queda da desigualdade de renda no Brasil. Ipea, 2006 (Nota técnica).

\section{Referências}

Barros, Ricardo Paes de; Henriques, Ricardo \& Mendonça, Rosane, In: A Estabilidade Inaceitável: Desigualdade e Pobreza no Brasil - Instituto de Pesquisas Econômicas Aplicadas, IPEA, 2001.

Barros, Ricardo Paes de; Carvalho, Mirela de; Franco, Samuel. Pobreza multidimensional no Brasil. Instituto de Pesquisas Econômicas Aplicadas, IPEA, 2006.

Bendix, Reinhard. Estado nacionaly ciudadanía. Buenos Aires: Amorrortu.

Bobbio, Norberto. A era dos direitos. Rio de Janeiro: Campus, 1992.

BrasiL, Lei no 10.836, Brasília, 2004a. 
BrasiL, Decreto n 5.209, Brasília, 2004b.

Brasil. Ministério do Desenvolvimento Social - MDS. Perfil das Famílias Beneficiárias do Programa Bolsa Família. Brasília. Dezembro, 2006.

BrasiL. Ministério do Desenvolvimento Social e Combate à Fome, Secretaria Nacional de Renda de Cidadania (2007), Módulo 6 da Capacitação a Distância de Técnicos e Gestores do Programa Bolsa Família, Programas Complementares, Brasília. Julho, 2007.

Brugué, Quim; Gomá, Ricard; Subirats, Joan. De la pobreza a la exclusión social: nuevos retos para las políticas públicas. Revista Internacional de Sociología (RIS), Tercera Época, n. 33, sept-dec, 2002, pp. 7-45.

Campbell, Tom - A Pobreza Como Violação dos Direitos Humanos: Justiça Global, Direitos Humanos e As Empresas Multinacionais. In: Pobreza E Desigualdade no BrasilTraçando Caminhos Para a Inclusão Social. Org: Jorge Werthein e Marlova Jovchelovitch Noleto, Brasília, UNESCO, 2004.

CASTEL, Robert. As metamorfoses da questão social: uma crônica do salário. Petrópolis: Ed. Vozes, 1999.

Castilho, José Roberto Fernandes. Cidadania: esboço de evolução e sentido da expressão. Acessado em: 11/06/2004. Disponível em: http://www.dhnet.org.br/direitos/ sos/textos/cid_expressao.html

Cravioto, J; Arrieta, R. Nutrition, mental development and learning. In:

Falkner, F., TAnNer, J. (eds). Human Growth: a comprehensive treatise, 2 ed., v. 3. New York: Plenum Press, 1986. http://www.mds.gov.br/secretarias/protecao_social_basica_ juventude.pdf http://www.mds.gov.br/institucional/o-ministerio/missao

Instituto Brasileiro de Geografia e Estatística (IBGE). Sintese de Indicadores Sociais. Rio de Janeiro, 2002.

Fleury, Sônia. A expansão da cidadania. Escola Brasileira de Administração Pública e de Empresas - EBAPE, 2004 (a), mimeo.

Políticas Sociais e Cidadania. Escola Brasileira de Administração Pública e de Empresas - EBAPE, 2004 (b), mimeo.

. Estados sem cidadãos. Rio de Janeiro: Ed. Fiocruz, 1994.

Folha de São Paulo. Bolsa Família exclui 2,2 milhões de famílias do benefício. Disponível em: http://www1.folha.uol.com.br/fsp/brasil/fc0701200902.htm.Acessado em: 07/01/ 2009.

Fraser, Nancy. Redistribución, reconocimiento y exclusión social. Universidad Javeriana. Inclusión Social y Nuevas Ciudadanias: condiciones para la convivencia y seguridad democraticas. Sem nario Internacional - Memorias. Colombia: Ed. UniJaveriana, 2003.

FrIEDLAND, Roge AlFORD, Robert R.. Bringing society back in: symbols, practices, and institutional contra dictions.

Fundação Univen sidade de Brasília. Projeto de Promoção do Desenvolvimento Local e Economia Solid ria - Fomento e apoio ao desenvolvimento local, com vista à geração 
de trabalho, emprego e renda: Aplicação de questionários e elaboração de diagnósticos. Secretaria Nacional de Economia Solidária, 2007, mimeo.

Instituto de Pesquisa Econômica Aplicada (IPEA). Revista Desafios do Desenvolvimento. 2007. Acessada em: 10/08/2009. Disponível em: http://desafios.ipea.gov.br/003/ 00301009.jsp?ttCD_CHAVE=2482 .

JunQUEIRA, L.A.P. Novas formas de gestão na saúde: descentralização e intersetorialidade. Saúde Social, 6(2): 31-46, 1997.

Kerstenetzky, Célia Lessa. Desigualdade e pobreza: lições sobre Amartya Sem. Revista Brasileira de Ciências Sociais, v. 15, n. 42, 2000.

Kymlicka, Will; Norman, Wayne. El retorno del ciudadano. Una revisión de la producción reciente en teoría de la ciudadanía. La Política - Revista de estudios sobre el Estado y la sociedad. Octubre, n. 3, 1997.

Marshall, T. H. Cidadania, classe social e status. Rio de Janeiro: Ed. Zahar, 1967, pp. $57-$ 114.

Medeiros, Marcelo, Brito, Tatiana \& Soares, Fábio: Programas Focalizados de Transferência de Renda no Brasil - IPEA, junho, 2007.

Menicucci, T.M.G. Gestão de Politicas Públicas: Estratégias Para Construção de Uma Agenda. Belo Horizonte, Fundação João Pinheiro, 2006.

Prebish, Raúl. Dependencia, interdependencia y desarrollo. Revista de La CEPAL, n. 34, Abril de 1988.

Relatório Sintético Sobre a Evolução dos Indicadores de Pobreza e Desigualdade no Ceará, elaborado pelos pesquisadores Flávio Ataliba Barreto e Carlos Alberto Manso, do Laboratório de Estudos da Pobreza (LEP), do Curso de mestrado em Economia (Caen), da Universidade Federal do Ceará (UFC). Para elaborar o levantamento, foram utilizados dados da Pesquisa Nacional por Amostra de Domicílios (Pnad) de 2005, do Instituto Brasileiro de Geografia e Estatística (IBGE).

ReIs, Liliane G. da Costa. Administração - Noções Gerais, Conceitos básicos. Disponível em: www.rits.org.br, julho de 2007.

Rezende Filho, Cyro de Barros; CÂmara Neto, Isnard de Albuquerque. A Evolução do Conceito de Cidadania. Departamento de Ciências Sociais e Letras da Universidade de Taubaté. SD.

Santos, Boaventura. Pelas mãos de Alice - o social e o político na pós modernidade. Lisboa: Afrontamento.

SEN, Amartya Kumar. Inequality Reexamined. Oxford University Press. 1992.

Silveira, Rosa Maria Godoy. 500 anos de uma cidadania excludente. Acessado em: 11/06/2004. Disponível em: http://www.dhnet.org.br/educar/

SouzA, Jessé. Política e desigualdade social. 2006, mimeo.

Young, Iris Marion. Polity and Group Difference: A Critique of the Ideal of Universal Citizenship. Ethics, no. 99. 1989. 
Democracia y justicia social. Universidad Javeriana. Inclusión Social y Nuevas Ciudadanias: condiciones para la convivencia y seguridad democraticas. Seminario Internacional - Memorias. Colombia: Ed. UniJaveriana, 2003.

World BAnK. Control and Accountability Mechanisms in Conditional Cash Transfer Programs: a review of programs in Latin America and the Caribbean. v. 1, n. 1, March, 2007. 


\section{Resumo-Resumen-Abstract}

Intersetorialidade e transversalidade: a estratégia dos programas complementares do Bolsa Família

Trajano Augustus Quinhões e Virginia Maria Dalfior Fava

O artigo analisa a estratégia implementada em 2006 e 2007 pelo Programa Bolsa Família (PBF) para a articulação de programas complementares às transferências condicionadas de renda, enfatizando sua contribuição para o enfrentamento da desigualdade e da exclusão social no Brasil, e apresenta resultados preliminares alcançados por alguns destes programas executados em nível federal. A articulação de programas complementares possibilita o reconhecimento de necessidades de grupos populacionais em situação de risco social e promove a oferta de ações específicas para as suas necessidades, para uma inclusão cidadã diferenciada. A estratégia implementada em 2006 e 2007 foi caracterizada pela intersetorialidade e transversalidade e a criação de um espaço propício para o desenvolvimento de inovações no campo das políticas sociais. Apesar do caráter recente dos programas complementares e das dificuldades de monitoramento, os resultados obtidos em programas federais e o comprometimento dos governos municipais na articulação de programas municipais demonstram que essa pode ser uma opção na agenda das políticas sociais dos três níveis de governo no Brasil.

Palavras-chave: Programa Bolsa Família, programas complementares, transversalidade e interdisciplinaridade.

Intersectorialidad y transversalidad: la estrategia de los programas complementarios al "Bolsa Família"

Trajano Augustus Quinhões y Virginia Maria Dalfior Fava

Analiza la estrategia implantada en los años 2006 y 2007 por el Programa Bolsa Família (PBF) para la articulación de programas complementarios a las transferencias condicionadas de rentas, enfatizando su contribución para el enfrentamiento de la desigualdad y de la exclusión social en Brasil. Presenta resultados preliminares obtenidos por algunos de eses programas implantados al nivel del gobierno federal. La articulación de programas complementarios posibilita el reconocimiento de las necesidades de grupos poblacionales en riesgo social, y promueve la oferta de acciones específicas para sus necesidades y para una inclusión social ciudadana diferenciada. La estrategia implantada en los años 2006 y 2007 fue caracterizada por la intersectorialidad y transversalidad, y la creación de un espacio oportuno/propicio para el desarrollo de innovaciones en el campo de las políticas públicas sociales. A pesar del carácter reciente de los programas complementarios y de las dificultades de control, los resultados obtenidos en los programas de nivel federal y el comprometimiento de los gobiernos municipales demuestran que esa opción es posible estar inserida en la agenda de las políticas sociales de los tres niveles de gobierno en Brasil.

Palabras clave: Programa Bolsa Família, programas complementarios, intersectorialidad y transversalidad.

Intergovernmental and among sectors approach: the strategy of the complementary programs to "Bolsa Família"

Trajano Augustus Quinhões and Virgínia Maria Dalfior Fava

The paper analyzes the strategy of Complementary Programs to the conditional cash transfers implemented in 2006 and 2007 by the Bolsa Familia Program (Family Grant Program), with a focus in the reduction of inequality and social exclusion in Brazil, and presents initial results of some of 
the programs that were implemented by the central government. The complementary programs require the identification and the governmental recognition of needs and vulnerabilities, and to give voice to specific groups and populations, promoting a distinct citizenship inclusion. The strategy had an approach among sectors and also an intergovernmental approach and created an innovative social policies environment. In spite of the complementary programs recent implementation and its difficulties in monitoring and evaluation, the results identified in some central government complementary programs and the municipalities commitment suggest that this strategy should be in the governmental agenda in the three levels of government in Brazil.

Keywords: Bolsa Família Program, complementary programs, intersectoral and intergovernmental approach.

Trajano Augustus Tavares Quinhões

É Especialista em Políticas Públicas e Gestão Governamental desde 1997. Em 2007 atuou como coordenadorgeral de Gestão do Programa Bolsa Família, no Ministério do Desenvolvimento Social e Combate à Fome. É economista pela Universidade Federal do Rio de Janeiro e doutor em Administração pela Escola Brasileira de Administração Pública e de Empresas, da Fundação Getúlio Vargas. Contato: trajano.quinhoes@mma.gov.br

Virgínia Maria Dalfior Fava

Atua na Coordenação-Geral do Programa Bolsa Família, no Ministério do Desenvolvimento Social e Combate à Fome, desde 2007. É psicóloga e mestre em Ciências do Comportamento pela Universidade de Brasília. Contato: virginiafava@gmail.com 